\title{
Correspondence \\ Manuka honey inhibits the development of Streptococcus pyogenes biofilms and causes reduced expression of two fibronectin binding proteins \\ Sarah E. Maddocks \\ smaddocks@cardiffmet.ac.uk \\ Received 11 August 2011 \\ Revised 29 November 2011 \\ Accepted 27 December 2011

\author{
Sarah E. Maddocks, Marta Salinas Lopez, Richard S. Rowlands \\ and Rose A. Cooper
} \\ Cardiff Metropolitan University, Western Avenue, Cardiff CF5 2YB, UK

\begin{abstract}
Streptococcus pyogenes (group A Streptococcus; GAS) is always of clinical significance in wounds where it can initiate infection, destroy skin grafts and persist as a biofilm. Manuka honey has broad spectrum antimicrobial activity and its use in the clinical setting is beginning to gain acceptance with the continuing emergence of antibiotic resistance and the inadequacy of established systemic therapies; novel inhibitors may affect clinical practice. In this study, the effect of manuka honey on S. pyogenes (M28) was investigated in vitro with planktonic and biofilm cultures using MIC, MBC, microscopy and aggregation efficiency. Bactericidal effects were found in both planktonic cultures and biofilms, although higher concentrations of manuka honey were needed to inhibit biofilms. Abrogation of adherence and intercellular aggregation was observed. Manuka honey permeated $24 \mathrm{~h}$ established biofilms of $S$. pyogenes, resulting in significant cell death and dissociation of cells from the biofilm. Sublethal concentrations of manuka honey not inhibit binding to fibrinogen. The observed inhibition of fibronectin binding was confirmed by a reduction in the expression of genes encoding two major fibronectin-binding streptococcal surface proteins, Sof and Sfbl. These findings indicate that manuka honey has potential in the topical treatment of wounds containing $S$. pyogenes.
\end{abstract} effectively prevented the binding of $S$. pyogenes to the human tissue protein fibronectin, but did
}

\section{INTRODUCTION}

Streptococcus pyogenes (group A Streptococcus) colonizes the nasopharynx and skin of healthy individuals, forming part of the commensal microbiota. Under appropriate conditions, S. pyogenes can be transmitted to wounds and is especially problematic after surgery, following skin grafting and for military personal with traumatic or puncture wounds. Wounds provide a route of entry to the host and damaged tissues display a matrix of proteins including collagen, albumin, fibronectin and fibrinogen, which collectively provide a plethora of ligands to which opportunistic pathogens, including streptococci, adhere (Kubo et al., 2001). Surgical site infection accounts for approximately $25 \%$ of all hospital-acquired infections and may result in the development of a non-healing or chronic wound (Werdin et al., 2009). Non-healing wounds are defined as wounds that have failed to proceed through the normal, orderly and timely reparative process that results in restoration of anatomical and functional integrity, within 3 months (Cooper, 2005; Guo \& Dipietro, 2010). In the developed world, approximately $1-1.5 \%$ of populations have non-healing wounds, and these account for 2 $4 \%$ of all health care expenses (Gottrup, 2008).
Biofilms have been associated with persistent or chronic wound infections and are a major obstacle to healing (James et al., 2008; Rhoads et al., 2008). Streptococcus species readily form biofilms, by a process in which numerous cell-wall-anchored adhesins specifically attach to human tissue protein ligands and promote bacterial aggregation (Nobbs et al., 2009; Maddocks et al., 2011; Thenmozhi et al., 2011). Examples of such surface adhesins include the pilus and F1/SfbI proteins which are encoded on the FCT (fibrinogen-collagen-T antigen) region of the genome as well as Sof, AgI/II and M protein, whose genes are located outside of the FCT region (Köller et al., 2010). Streptococci differ in their capacity to form biofilms but in every instance, the process relies initially upon adhesion to a given substratum, followed by a period of proliferation prior to the establishment of a stable microbial community (Kreikemeyer et al., 2011).

Honey has had a valued place in traditional medicine for many centuries and was reintroduced into modern medicine during the 21st century. Honey exhibits broad spectrum antibacterial activities and has been reported to inhibit more than 80 species of bacteria, including meticillin-resistant Staphylococcus aureus, vancomycin-resistant enterococci, 
Lancefield groups A, C and G streptococci, Pseudomonas aeruginosa and Actinomyces species (Molan, 1992; Cooper et al., 2002a, b; Blair et al., 2009). The antibacterial properties of many honeys are associated with hydrogen peroxide but methylglyoxal has been shown to be important in manuka honey (Mavric et al., 2008). The precise intracellular effects of manuka honey are beginning to be understood and bacterial cell damage is mediated via diverse processes that so far appear to be species-specific (Henriques et al., 2010, 2011; Jenkins et al., 2011a, b). Preliminary data derived from studies of Streptococcus mutans and clinical isolates of $S$. pyogenes have shown that biofilm development is disrupted by manuka honey, but the processes involved remain largely unknown (Badet \& Quero, 2011; Cooper et al., 2011). Therefore, this study was undertaken to determine the in vitro effect of manuka honey against biofilms of $S$. pyogenes (MGAS6180; M28), a well characterized strain associated with invasive disease and which has been the subject of numerous biofilm studies, and to establish whether manuka honey disrupted binding of streptococci to human wound proteins fibrinogen and fibronectin.

\section{METHODS}

Bacterial strains. S. pyogenes MGAS6180 (M28, invasive disease; Green et al., 2005) was grown in Todd-Hewitt (TH) broth (Oxoid) containing $0.5 \%$ yeast extract; Bacto agar (Difco) was added to achieve a $1.4 \%(\mathrm{w} / \mathrm{v})$ final concentration in agar plates. Cultures were incubated at $37{ }^{\circ} \mathrm{C}$ in air supplemented with $5 \% \mathrm{CO}_{2}$. For analysis of aggregation properties, $S$. pyogenes was grown in $\mathrm{C}$ medium containing $0.2 \%$ glucose (Lyon et al., 1998).

Medical grade manuka honey. Sterile medical grade manuka honey (Medihoney) was kindly donated by Comvita. Medihoney was provided in sterile $50 \mathrm{~g}$ portions.

Minimum inhibitory and bactericidal concentrations. The MIC for manuka honey against planktonically grown $S$. pyogenes MGAS6180 was determined by serial dilution $(0-95 \%$; w/v) in a total volume of $5 \mathrm{ml}$ iso-sensitest broth (Oxoid) (according to the British Society for Antimicrobial Chemotherapy methodology for determining MIC; Andrews, 2011). Cultures were incubated for $16 \mathrm{~h}$ at $37{ }^{\circ} \mathrm{C}$ in aerobic conditions with $5 \% \mathrm{CO}_{2}$. To establish the $\mathrm{MBC}$, samples corresponding to the MIC and including three samples of a higher concentration were plated onto Todd-Hewitt agar and incubated for $16 \mathrm{~h}$ at $37{ }^{\circ} \mathrm{C}$ in aerobic conditions with $5 \% \mathrm{CO}_{2}$. Assays were done in triplicate on each of three separate occasions.

Inhibition of bacterial growth. To determine the extent of growth inhibition by manuka honey, triplicate cultures of $S$. pyogenes MGAS6180 were grown for $8 \mathrm{~h}$ at $37^{\circ} \mathrm{C}$ in $10 \mathrm{ml} \mathrm{TH}$ broth, in aerobic conditions with $5 \% \mathrm{CO}_{2}$, supplemented with manuka honey $(0,20$ and $40 \% \mathrm{w} / \mathrm{v})$. Bacterial growth was monitored at $\mathrm{OD}_{650}$ at hourly intervals. Growth experiments also utilized triplicate biological samples.

Aggregation assays. S. pyogenes MGAS6180 was initially grown in $\mathrm{C}$ medium for $16 \mathrm{~h}$ (Lyon et al., 1998) and harvested by centrifugation at $5000 \mathrm{~g}$ for $10 \mathrm{~min}$. Bacterial cell pellets were resuspended in either $1 \mathrm{ml} \mathrm{C}$ medium or an appropriate concentration of manuka honey ( 5 and $10 \%$; w/v) dissolved in $\mathrm{C}$ medium and the $\mathrm{OD}_{600}$ of the culture was adjusted to $1.0( \pm 0.05)$ if necessary. In both cases, manuka honey at twice the desired concentration was dissolved in double strength $\mathrm{TH}$ and diluted to the required concentration using $\mathrm{TH}$; cell pellets were resuspended in either 5 or $10 \%(\mathrm{w} / \mathrm{v})$ honey solutions. In an untreated control, manuka honey was replaced with PBS added to maintain the appropriate volume and concentration of TH media. Aggregation assays were carried out in triplicate as described previously (Jakubovics et al., 2005). Briefly, cell suspensions were incubated statically at $37{ }^{\circ} \mathrm{C}$ in $1.5 \mathrm{ml}$ semimicrocuvettes and $\mathrm{OD}_{600}$ readings were taken at $30 \mathrm{~min}$ intervals over a period of $6 \mathrm{~h}$ to monitor the extent of bacterial aggregation. Bacterial aggregation was monitored by observing a reduction on the $\mathrm{OD}_{600}$ over $6 \mathrm{~h}$. Controls containing no manuka honey were analysed simultaneously. Aggregation was expressed as a percentage fall in $\mathrm{OD}_{600}$ relative to the control; triplicate biological samples were assayed and statistical analysis (Students $t$-test to compare 5 and $10 \%$ honey treatment, individually, to the no honey control) was undertaken using Minitab (version 14).

Static biofilm model. S. pyogenes MGAS6180 was initially grown in $\mathrm{C}$ medium for $16 \mathrm{~h}$ and these stationary phase cultures were harvested by centrifugation and adjusted to $\mathrm{OD}_{650} 0.1$. To determine whether manuka honey prevented biofilm formation, biofilms were established in 96-well microtitre plates (Greiner) in $50 \mu \mathrm{l} \mathrm{TH}$, supplemented with manuka honey $(0,10,20$ and $40 \% \mathrm{w} / \mathrm{v})$, by inoculating each well with $5 \mu \mathrm{l}$ harvested cells. Plates were incubated at $37{ }^{\circ} \mathrm{C}$ for $24 \mathrm{~h}$, aerobically with $5 \% \mathrm{CO}_{2}$. To estimate biomass, unattached cells were gently aspirated and discarded, and adherent cells were washed twice with PBS and stained with crystal violet $(0.25 \%$; w/v) for $10 \mathrm{~min}$; following a further two washes with PBS, cell-bound crystal violet was resolubilized with $7 \%$ acetic acid, and absorbance was measured at $595 \mathrm{~nm}\left(A_{595}\right)$ (Jakubovics et al., 2005). To determine whether manuka honey disrupted established biofilms of $S$. pyogenes MGAS6180, biofilms were cultivated in 96-well microtitre plates for $24 \mathrm{~h}$ at $37^{\circ} \mathrm{C}$, as described above in TH medium in the absence of manuka honey. Biofilms were washed twice with PBS, and $50 \mu \mathrm{l}$ manuka honey dissolved in TH medium $(0,10,20$ and $40 \% \mathrm{w} / \mathrm{v})$ was added to each well; the plates were incubated at $37^{\circ} \mathrm{C}$ for a further $2 \mathrm{~h}$ after which time they were stained with crystal violet, as described above. To establish the effect of a sublethal dose of manuka honey on biofilm structure, biofilms were grown as described above for $24 \mathrm{~h}$, but on $15 \mathrm{~mm}$ glass coverslips in 24-well microtitre plates. Coverslips were washed with PBS and were stained using crystal violet $(0.25 \%$; $\mathrm{w} / \mathrm{v})$ before being visualized by light microscopy $(\times 1000$ magnification). All experiments were carried out in triplicate, using three different biological samples; Minitab (version 14) was employed for statistical analysis (Students $t$-test comparing the reduction in biomass using each honey treatment, individually, to the untreated control).

Live-Dead staining. Images of bacterial cells were collected for control cells (untreated) and for cells treated with $40 \%$ (w/v) manuka honey for $2 \mathrm{~h}$, to determine the effect of manuka honey on viability. Biofilms were grown in Petri dishes in $5 \mathrm{ml} \mathrm{TH}$ media, or $5 \mathrm{ml} 40 \%$ (w/v) honey dissolved in TH media, as previously described; liquid was aspirated from the plates and biofilms were washed with $1 \mathrm{ml}$ PBS. Biofilms were scraped from the coverslips using a cell scraper, resuspended in $1 \mathrm{ml}$ PBS and stained with Live-Dead BacLight bacterial viability kit (Invitrogen), following the manufacturer's instructions. Fluorescence microscopy images were obtained using a Nikon Eclipse 80i fluorescent microscope with oil immersion and $\times 100$ lens. For detection of SYTO 9 (green channel) a $488 \mathrm{~nm}$ excitation and $520 \mathrm{~nm}$ emission filter was used. For propidium iodide detection (red channel) a $543 \mathrm{~nm}$ excitation and $572 \mathrm{~nm}$ emission filter was used. Image analysis used Volocity Software (PerkinElmer).

Biofilm disruption. To determine whether manuka honey affected biofilm biomass by facilitating the dissociation of adherent cells from 
the biofilm, assays were conducted to monitor the numbers of viable planktonic cells that were released into the liquid phase, from established biofilms following treatment with manuka honey. Biofilms were grown for $24 \mathrm{~h}$ as described above. The liquid was aspirated from each well, biofilms were washed twice with PBS to remove any planktonic or loosely adherent cells, and manuka honey over a range of concentrations [0,10,20 and $40 \%(\mathrm{w} / \mathrm{v})$, respectively] was added to the $24 \mathrm{~h}$ established biofilms. Following the application of honey, biofilms were incubated for a further $2 \mathrm{~h}$ at $37^{\circ} \mathrm{C}$ as above and samples of the liquid above the biofilm were collected at $30 \mathrm{~min}$ intervals. Bacterial cells were enumerated using the total viable cell (TVC) counting method described by Miles et al. (1938) with TH agar as a non-selective medium. The number of recovered cells was calculated as c.f.u. $\mathrm{ml}^{-1}$.

Fibronectin- and fibrinogen-binding assays. To determine the effect of manuka honey on adherence of $S$. pyogenes cells to immobilized fibronectin and fibrinogen, a crystal violet assay was conducted as described previously, using $1 \%$ BSA to block wells prior to assaying cell binding (Jakubovics et al., 2005, 2009). Nunc highbind 96-well microtitre plates were coated with $1 \mu \mathrm{g}$ each protein dissolved in coating buffer $\left(20 \mathrm{mM} \mathrm{Na} \mathrm{CO}_{3}, 20 \mathrm{mM} \mathrm{NaHCO}\right.$; $\mathrm{pH}$ 9.3). This amount of fibronectin and fibrinogen was found to be optimal for bacterial binding (data not shown). Manuka honey at $20 \%(\mathrm{w} / \mathrm{v})$ was used to determine whether binding was inhibited, and the manuka honey was dissolved in Tris-buffered saline (TBS; $\mathrm{pH}$ 7.4). Cells were grown for $16 \mathrm{~h}$ in $\mathrm{TH}$ prior to the assay, harvested as above, resuspended in TBS with or without manuka honey $(20 \%$ $\mathrm{w} / \mathrm{v})$, and $50 \mu \mathrm{l}$ was inoculated into a microtitre plate. Absorbance values $\left(A_{595}\right)$ were compared against a PBS control throughout the entire procedure; the assay also included a control set of wells containing only coating buffer without protein ligands to determine whether the wells of the plate were sufficiently coated. The experiments used triplicate biological replicates and each assay was performed in triplicate; statistical analysis used Minitab (version 14; Students $t$ test).

RNA extraction from S. pyogenes biofilms. Large scale, static biofilms of $S$. pyogenes were grown in duplicate in $5 \mathrm{ml} \mathrm{C}$ medium (with $20 \%$ honey for the 'treated' biofilms) in sterile Petri dishes for $24 \mathrm{~h}$ at $37^{\circ} \mathrm{C}$, as for the small scale biofilms. The liquid was aspirated and the biofilm was scraped from the surface of the Petri dish using a sterile cell scraper. Biofilms were resuspended in $500 \mu \mathrm{l} \mathrm{PBS}$ and vortexed for $1 \mathrm{~min}$ to break up cell aggregates. Honey-treated and untreated cell suspensions were equilibrated (to approximately $2.5 \times 10^{9}$ c.f.u.) prior to treatment with mutanolysin $(100 \mu \mathrm{g})$ and lysozyme $(100 \mu \mathrm{g})$ for $20 \mathrm{~min}$ at $37^{\circ} \mathrm{C}$. RNA extraction was carried out using the SV Wizard total RNA extraction kit (Promega) according the manufacturer's instructions. RNA quantification was performed by spectrophotometric measurement using a NanoDrop ND-1000 (NanoDrop Technologies) and each RNA sample was adjusted to give a final concentration of $10 \mathrm{ng}^{-1} \mathrm{l}^{-1}$.

End point RT-PCR to determine the relative expression of sof and $\boldsymbol{s f b l}$. PCR primers were designed to amplify a $1100 \mathrm{bp}$ fragment of the sof gene (sof-fwd: $5^{\prime}$-ACTTAGAAAGTTATCTGTAGGG; sofrev: 5'-TCTCTCGAGCTTTATGGATAG) and $1200 \mathrm{bp}$ fragment of the $s f b I$ gene ( $s b f I$-fwd: $5^{\prime}$-AACTGCTTTAGGAACAGCTTC; $s b f I$-rev: 5 -CCACCATAGCCACAATGCT). The complete genome sequence for S. pyogenes MGAS6180 was obtained from the NCBI database (www.ncbi.nlm.nih.gov) and used as a basis to design the primers used in this study. Internal control primers were designed to amplify a $900 \mathrm{bp}$ internal fragment of the $g l r$ ( $m u r I$; glutamate racemase) gene ( $g r$-fwd: 5 '-ATGGATACAAGACCAATTGGG; $g l r$-rev: 5 '-TCATAAGGTGACATGCTCCAC), a known housekeeping gene in $S$. pyogenes that is commonly used for MLST (http://spyogenes.mlst.net/misc/ info.asp) (Kalia et al., 2001; Enright et al., 2001). RNA was pre-treated with DNase I (Promega) prior to end point RT-PCR according to the manufacturer's instructions. RNA was reverse transcribed using the Access RT-PCR system (Promega). PCRs were performed in $25 \mu \mathrm{l}$ reactions containing $50 \mathrm{ng}$ template, $10 \mathrm{mM}$ dNTPs, $1 \mu \mathrm{M}$ oligonucleotides, PCR buffer, $4.5 \mathrm{mM} \mathrm{MgCl}_{2}$ and $5 \mathrm{U}$ polymerase. PCRs were performed under the following conditions: denaturation at $94{ }^{\circ} \mathrm{C}$ for $5 \mathrm{~min}$, followed by 40 cycles of $94{ }^{\circ} \mathrm{C}$ for $30 \mathrm{~s}, 53{ }^{\circ} \mathrm{C}$ for $30 \mathrm{~s}, 68{ }^{\circ} \mathrm{C}$ for $2 \mathrm{~min}$, and a final elongation at $68{ }^{\circ} \mathrm{C}$ for $7 \mathrm{~min}$. The positive control for the reaction was provided by the manufacturer (Promega), and nano-pure water was used to exclude the possibility of contamination. Band intensities were compared under UV light after samples had been separated by electrophoresis through a $0.8 \%$ agarose gel. Densitometry was performed using the Bio-Rad GelDoc 2000 (Bio-Rad) and Quantity One software (Bio-Rad). This part of the study used three biological replicates and densitometric results were analysed by Students $t$-test using Minitab (version 14).

\section{RESULTS}

\section{Inhibition of planktonic S. pyogenes by manuka honey}

The MIC of manuka honey against $S$. pyogenes MGAS6180 was found to be $20 \%(\mathrm{w} / \mathrm{v})$ and the MBC was found to be $45 \%(\mathrm{w} / \mathrm{v})$. Growth curves with $20 \%$ (w/v) manuka honey resulted in a reduced growth rate and reduction in overall cell number (Fig. 1) over a period of $8 \mathrm{~h}$, compared with cells grown without honey. Growth curves conducted with $40 \%(\mathrm{w} / \mathrm{v})$ manuka honey resulted in no growth of S. pyogenes MGAS6180. Additionally, time-kill assays (Ogunmwonyi et al. 2010; Jenkins et al. 2011b) over $24 \mathrm{~h}$ indicated that $S$. pyogenes could not be recovered after $8 \mathrm{~h}$ incubation with $45 \%(\mathrm{w} / \mathrm{v})$ manuka honey (data not shown), supporting the data obtained for the MBC.

\section{S. pyogenes aggregation and biofilm development are inhibited by sublethal concentrations of manuka honey}

To test the capacity for manuka honey to inhibit intercellular aggregation, suspensions of S. pyogenes MGAS6180 were

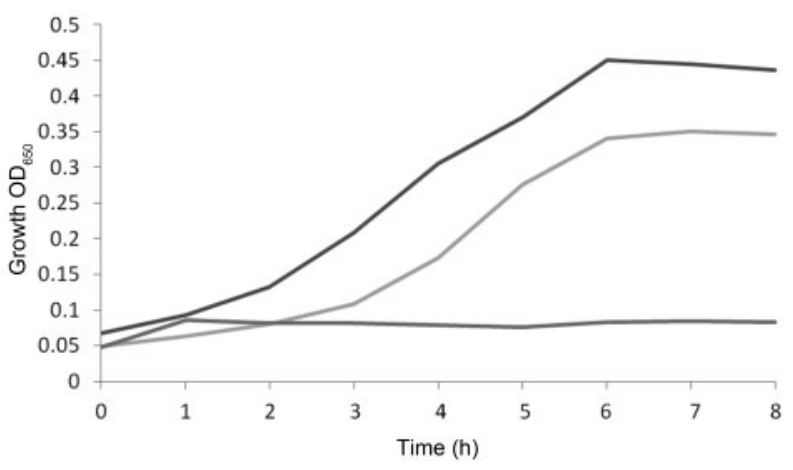

Fig. 1. Growth analysis of $S$. pyogenes MGAS6180 treated with manuka honey. Dark, light and mid grey indicate 0, 20 and $40 \%$ $(w / v)$ manuka honey, respectively. 
mixed with $10 \%(\mathrm{w} / \mathrm{v})$ manuka honey. In the absence of manuka honey, cells strongly aggregated but in the presence of $10 \%(\mathrm{w} / \mathrm{v})$ honey, aggregation was completely inhibited $(P<0.05)$ (Fig. 2.). To determine whether this response was dose-dependent, the honey was diluted $5 \%(\mathrm{w} / \mathrm{v})$, which is four times lower than the MIC (Fig. 2). At this concentration, aggregation was inhibited as effectively as with $10 \%(\mathrm{w} /$ v) manuka honey $(P<0.05)$.

When biofilms of $S$. pyogenes were initiated in the presence of 10,20 and $40 \%(\mathrm{w} / \mathrm{v})$ manuka honey, a statistically significant reduction in biomass was observed in each case. A reduction of $75 \%(P=0.03)$ was observed with $10 \%(\mathrm{w} /$ v) manuka honey; 20 and $40 \%(w / v)$ manuka honey resulted in between $90 \%(P=0.02)$ and $96 \%(P=0.01)$ reduction in biomass, respectively (Fig. 3). Images of $S$. pyogenes biofilms obtained by light microscopy confirmed these observations, because cells exposed to $20 \%(\mathrm{w} / \mathrm{v})$ manuka honey showed no evidence of microcolony formation and contained only long chains of cells, some of which were enlarged (Fig. 4).

\section{Manuka honey facilitates cell death and dissociation of bacterial cells from established $\mathbf{S}$. pyogenes biofilms}

To determine the effect of manuka honey against established biofilms of $S$. pyogenes MGAS6180, biofilms were grown for $24 \mathrm{~h}$ prior to honey treatment. Following $2 \mathrm{~h}$ treatment with 10 and $20 \%$ manuka honey $(\mathrm{w} / \mathrm{v})$, a $72 \%(P=0.32)$ and $77 \%(P=0.08)$ reduction in biomass was observed, respectively. Following treatment for $2 \mathrm{~h}$ with $40 \%(\mathrm{w} / \mathrm{v})$ manuka honey, the observed reduction in biofilm biomass was even greater, and statistically significant at $85 \%(P=0.01)$ (Fig. 5a). Biofilms were subsequently scraped from the plate and analysed using the Miles and Misra technique (Miles et al., 1938). From biofilms established in the absence of manuka honey,

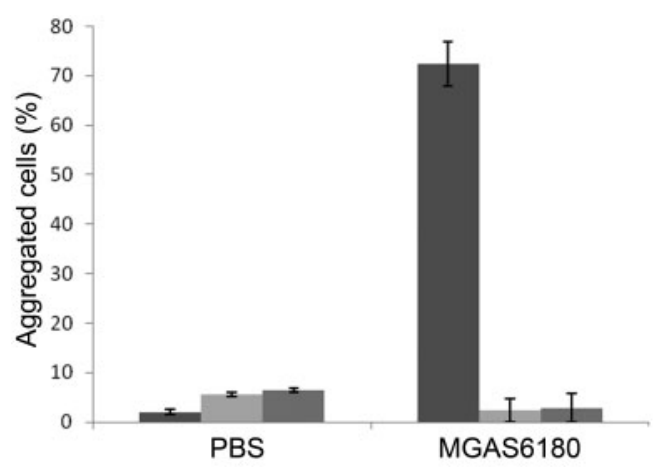

Fig. 2. Aggregation assay. Cells were assayed for aggregation after $6 \mathrm{~h}$ and the level of aggregation was compared with a PBS control. Dark, light and mid grey indicate 0, 5 and $10 \%(w / v)$ manuka honey, respectively. Error bars show SEM.

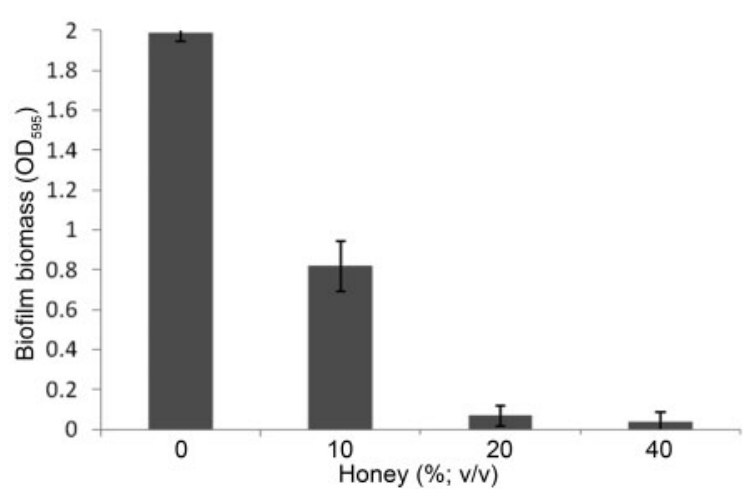

Fig. 3. The disruption of biofilm development using manuka honey. Biofilms of $S$. pyogenes MGAS6180 were grown for $24 \mathrm{~h}$ in media supplemented with manuka honey at 10,20 and $40 \%(\mathrm{w} / \mathrm{v})$. Error bars show SEM.

$4 \times 10^{6}$ c.f.u. was recoverable from biofilms. There was an approximately twofold reduction following treatment with 10 and $20 \%(\mathrm{w} / \mathrm{v})$ manuka honey, corresponding to $1.93 \times 10^{6}$ c.f.u. and $1.22 \times 10^{6}$ c.f.u., respectively (Fig. $5 \mathrm{a}$ ). The reduction in viable cells was even more marked using $40 \%(\mathrm{w} / \mathrm{v})$ manuka honey, resulting in a viable count of $2.4 \times 10^{5}$ c.f.u.

Live-Dead viability staining (Invitrogen) of untreated biofilms grown for $24 \mathrm{~h}$ at $37{ }^{\circ} \mathrm{C}$, honey-treated $(40 \% \mathrm{w} /$ v) biofilms grown for $24 \mathrm{~h}$ at $37{ }^{\circ} \mathrm{C}$, and biofilms that were grown for $24 \mathrm{~h}$ at $37{ }^{\circ} \mathrm{C}$, then treated for $2 \mathrm{~h}$ with $40 \%$ (w/ v) manuka honey, showed that in both cases, the honey treatment resulted in cell death (Fig. 5b). For both honey treatment conditions, more non-viable cells were present than viable cells; in the untreated control, no non-viable cells were observed. These data suggested that the honey treatment resulted in cell death and supported the TVC data described above.

With time, bacterial cells may dissociate from a biofilm. To determine whether manuka honey facilitated the dissociation of $S$. pyogenes from biofilms, the levels of planktonic cells in the liquid phase were monitored for $2 \mathrm{~h}$ following the application of manuka honey (the biofilm data described above showed that the biomass was reduced following $2 \mathrm{~h}$ treatment, so this time period was deemed appropriate for these experiments). Immediately after application of the manuka honey $(0 \mathrm{~min})$ the c.f.u. was approximately the same for each condition. After $30 \mathrm{~min}$ and throughout the duration of the experiment $(120 \mathrm{~min})$, higher c.f.u. values were recovered from biofilms treated with 10 and $20 \%$ (w/v) manuka honey (subinhibitory concentrations) compared with untreated biofilms, with a maximum recovery of $1.2 \times 10^{6}$ c.f.u. (Fig. 5 c). However, fewer cells were recovered from biofilms exposed to $40 \%$ $(\mathrm{w} / \mathrm{v})$ manuka honey, despite this concentration being lower than the observed MBC. 
(a)

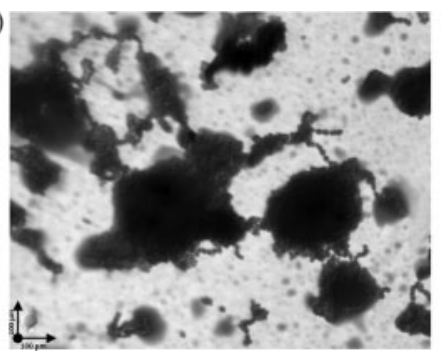

(b)

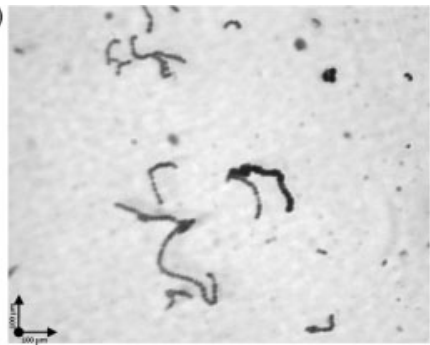

Fig. 4. Disruption of microcolony development using a sublethal dose of manuka honey (20\% $\mathrm{w} / \mathrm{v})$. Biofilms of $S$. pyogenes were grown on glass coverslips for $24 \mathrm{~h}$ and stained with $0.25 \%$ (w/v) crystal violet; images were viewed by light microscopy using oil immersion at $\times 1000$ magnification. Biofilms were grown with $0(a)$ or $20 \%(w / v)$ (b) manuka honey.

\section{Sublethal concentrations of manuka honey inhibit binding of $S$. pyogenes to a wound-associated ligand}

To establish whether manuka honey affected binding of $S$. pyogenes MGAS6180 to the wound-associated proteins fibronectin and fibrinogen, $1 \mu \mathrm{g}$ of each of these two protein ligands was immobilized to the surface of a microtitre plate. The extent of binding inhibition using a sublethal dose $(20 \% \mathrm{w} / \mathrm{v})$ of manuka honey was compared with adherence observed in the absence of manuka honey. Binding of $S$. pyogenes to fibronectin in the presence of $20 \%(\mathrm{w} / \mathrm{v})$ manuka honey was reduced by $74 \%$, which was found to be statistically significant $(P=0.01)$; conversely no such reduction in binding was observed for fibrinogen $(P=0.38)$ (Fig. 6). This is the first time that evidence to suggest that manuka honey has the potential to inhibit binding to human protein ligands has been reported.

\section{Genes encoding the surface adhesins Sof and Sbfl are differentially expressed in response to exposure to a sublethal concentration of manuka honey}

To determine whether the decreased binding to fibronectin was the result of differential expression of two of the major fibronectin-binding proteins (Sof and SfbI) of $S$. pyogenes MGAS6180 in response to sublethal concentrations of honey, end point RT-PCR was employed. The PCR products were analysed by densitometry and quantified relative to the New England Biolabs $1 \mathrm{~kb}$ quantitative molecular mass

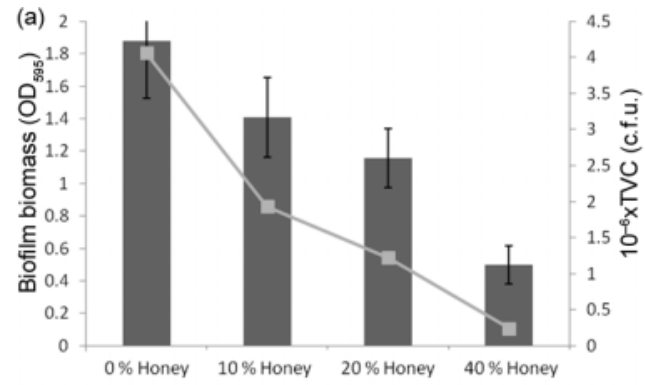

(b)
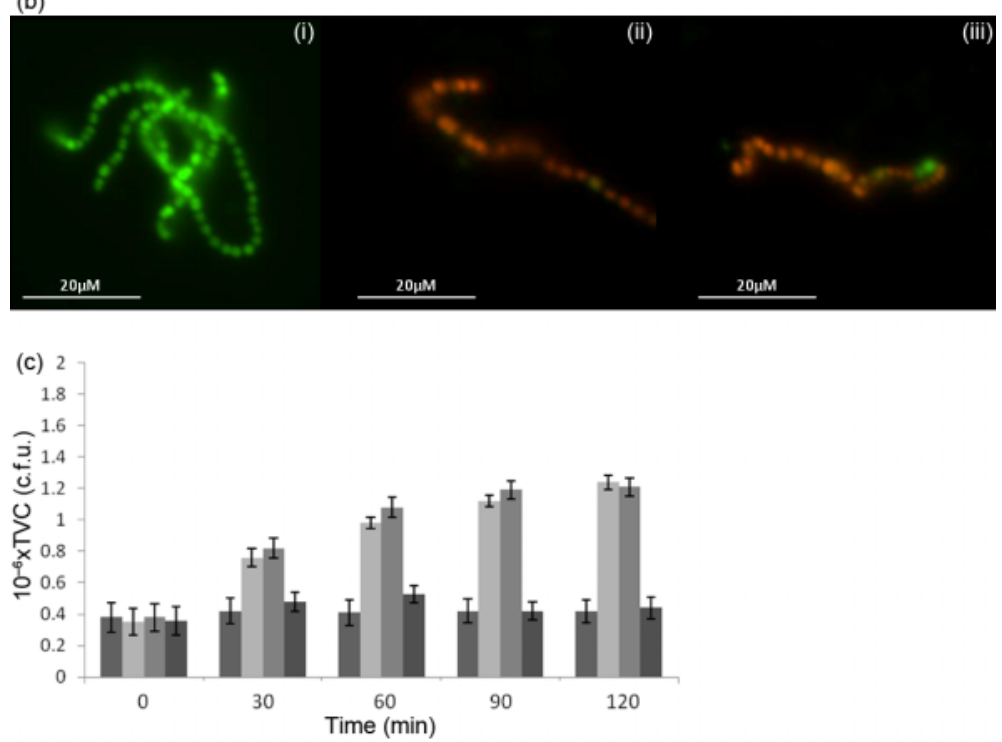

Fig. 5. (a) The disruption of established biofilms of $S$. pyogenes MGAS6180 using manuka honey and the corresponding reduction in viable cells. Dark grey bars show biofilm biomass ( $($ SEM); the pale grey line corresponds to TVC. Biofilms were grown for $24 \mathrm{~h}$ and treated with manuka honey at 10,20 and $40 \%(\mathrm{w} / \mathrm{v})$ for $2 \mathrm{~h}$. TVC was determined using the method described by Miles et al. (1938). (b) Live-Dead viability staining of honeytreated and untreated biofilms of $S$. pyogenes. Biofilms were resuspended in PBS prior to staining. Green SYTO 9-stained cells are viable, red propidium iodide-stained cells are non-viable. (i) Untreated control cells, (ii) biofilm grown for $24 \mathrm{~h}$ with $40 \%(\mathrm{w} / \mathrm{v})$ manuka honey, (iii) biofilm grown for $24 \mathrm{~h}$, then subsequently treated with $40 \%(\mathrm{w} / \mathrm{v})$ manuka honey for $2 \mathrm{~h}$. (c) Recovery of detached bacterial cells from biofilms of $S$. pyogenes MGAS6180 that were grown for $24 \mathrm{~h}$ and then treated with manuka honey for $2 \mathrm{~h}$. Viable cells were sampled immediately after application of honey and recovered on non-selective agar (TH). From left to right (grey, pale, mid and dark grey) indicate $0,10,20$ and $40 \%(\mathrm{w} / \mathrm{v})$ manuka honey. Error bars show SEM. 


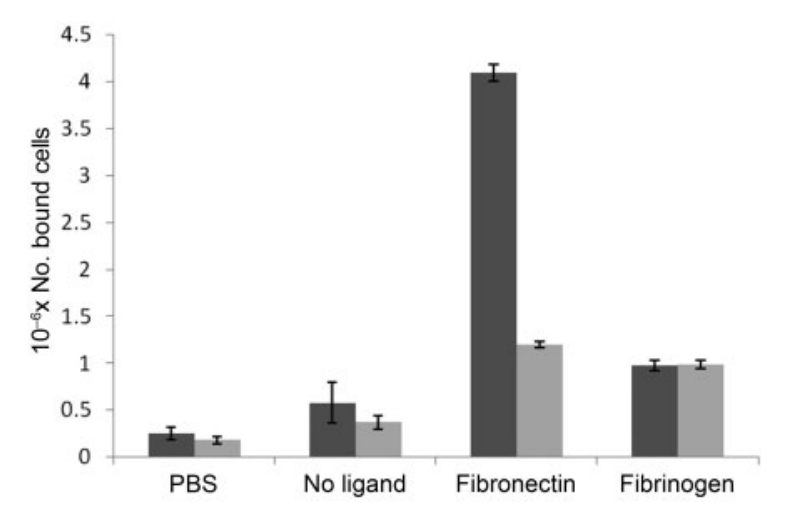

Fig. 6. Determining the effect of a sublethal concentration of manuka honey on the ability of $S$. pyogenes MGAS6180 to bind fibronectin and fibrinogen, compared with PBS as a control, and with coating buffer only (no ligand). Dark and light grey bars indicate 0 and $20 \%$ (w/v) manuka honey, respectively. Error bars show SEM.

marker (thresholds for detection $\geqslant 0.15 \mathrm{nmol}$ ). The results confirmed that both $s f b I$ and sof were expressed to a lesser extent in the presence of $20 \%(\mathrm{w} / \mathrm{v})$ manuka honey (Fig. 7). Specifically, for $s b f I$ there were $1.49 \mathrm{nmol}$ PCR product in the $20 \%$ (w/v) manuka honey conditions, compared with $2.16 \mathrm{nmol}$ with $0 \%$ manuka honey, which equates to a $31 \%$ reduction in expression. For sof in the presence of $20 \%$ $(\mathrm{w} / \mathrm{v})$ manuka honey, the amount of PCR product was below the threshold of detection; without manuka honey, $1.73 \mathrm{nmol}$ was produced, suggesting that the expression of sof was also reduced following treatment with a sublethal concentration of honey. The equal amounts of $g l r$ product $[2.03 \mathrm{nmol}$ with no manuka honey and $2.02 \mathrm{nmol}$ with $20 \%(\mathrm{w} / \mathrm{v})$ manuka honey] confirmed that equal amounts of RNA were used in these reactions and that the expression of this gene was not affected by honey treatment. Statistical analysis of the three biological replicates showed that there was no differential expression for $g l r$ under both conditions; for $s f b I$, the difference was statistically significant $(P<0.05)$. In all instances sof could not be detected by densitometry following honey treatment.

\section{DISCUSSION}

Wounds that are infected with $S$. pyogenes often fail to respond to treatment. This is not always the consequence of factors that confer antibiotic resistance and a growing body of evidence strongly suggests that this phenomenon is attributed to the tendency of $S$. pyogenes to grow as a biofilm during infection. Over $90 \%$ of invasive and noninvasive strains readily form biofilms, and despite information regarding biofilm formation in $S$. pyogenes being limited, it is becoming apparent that this characteristic is both strain- and serotype-dependent (Baldassarri et al., 2006; Maddocks et al., 2011). S. pyogenes strains routinely isolated from patients who have experienced treatment failure are all prolific biofilm formers (Lembke et al., 2006) that do not necessarily exhibit resistance to commonly used systemic antibiotics; it is the biofilm community itself that appears to confer resistance (Conley et al., 2003).

Currently most studies on the efficacy of honey against biofilms of $S$. pyogenes have used uncharacterized clinical isolates and in some cases local honeys (Al-Waili et al., 2005; Voidarou et al., 2011). This study describes the first systematic analysis of the effect of medical grade manuka honey on developing and established biofilms of a wellcharacterized strain of invasive S. pyogenes (MGAS6180). In addition to this, this study provides the first evidence, to our knowledge, that manuka honey can specifically inhibit adherence of S. pyogenes MGAS6180 to fibronectin. This is especially significant with regard to wound infection because high levels of fibronectin are exposed in wounds as a consequence of tissue damage, thus providing a ligand to which $S$. pyogenes can bind.

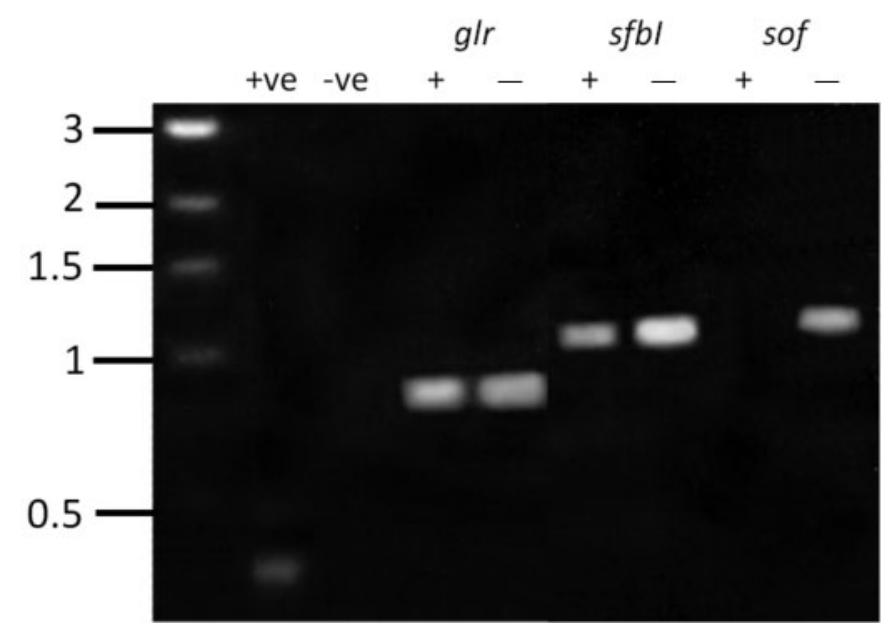

Fig. 7. End point RT-PCR to determine the amount of sfb/ and sof expressed by biofilms of $S$. pyogenes MGAS6180 when treated with a sublethal $(20 \% \mathrm{w} / \mathrm{v})$ concentration of manuka honey. +ve indicates the positive control (Promega); -ve indicates the negative control $\left(\mathrm{dH}_{2} \mathrm{O}\right)$; glutamate racemase $(\mathrm{g} / \mathrm{r})$ is an internal control. + indicates honey treatment; - indicates no honey treatment. Values for the molecular mass marker are given in $\mathrm{kb}$. 
Concentrations of manuka honey equivalent to the MIC for planktonically grown cells were able to prevent biofilm development; manuka honey applied at just $5 \%$ less than the $\mathrm{MBC}$ for planktonically grown cells resulted in an almost complete abrogation of biofilm development. In both cases, there was undoubtedly some degree of growth inhibition as observed from the growth studies. However, the large reduction in biofilm biomass using the MIC did not support the small reduction in growth using the same concentration of manuka honey, suggesting that the loss of biofilm biomass was the consequence of more than growth inhibition alone. Treatment of established biofilms of $S$. pyogenes with manuka honey also facilitated a reduction in biofilm biomass. Since these biofilms had been grown for $24 \mathrm{~h}$ prior to treatment, the observed reduction in biomass was likely the result of cell death, which was verified by LiveDead viability staining which showed that non-viable cells were present in both developing and established biofilms that were treated with manuka honey. It was possible that the reduced TVCs could have been the result of a proportion of the population being in a viable but non-culturable state, which often occurs in response to cellular stress. This would have meant that the reduction in TVC observed might not have been attributed solely to cell death. However, the viability staining showing the presence of non-viable cells suggested that this was unlikely to be the case.

Lectins derived from Talisia esculenta and proteins derived from the seeds of Labramia bojeri are similarly known to effectively inhibit the capacity of strains of $S$. sobrinus and $S$. mutans to adhere to a polystyrene substratum and develop into a confluent biofilm (Oliveira et al., 2007). These are naturally derived products that lack the antimicrobial activity observed for manuka honey. More recently, honey has also been shown to reduce biofilm formation of $S$. mutans at 12.5 and $25 \%(\mathrm{w} / \mathrm{v})$ (Nassar et al., 2012). In addition to this, manuka honey is also documented to be effective against biofilms of Staphylococcus aureus and $P$. aeruginosa, both of which are wound-associated pathogens, making it a versatile topical treatment (Alandejani et al., 2009; Merckoll et al., 2009; Okhiria et al., 2009).

Many streptococcal surface adhesins perform a dual role mediating intracellular aggregation and surface adhesion; this is certainly true for S. pyogenes in which major biofilmassociated adhesins such as AspA and pili also facilitate autoaggregation (Edwards et al., 2008; Okahashi et al., 2010; Maddocks et al., 2011). Manuka honey was found to prevent autoaggregation of $S$. pyogenes at sublethal concentrations, of 5 and $10 \%(\mathrm{w} / \mathrm{v})$, demonstrating the significant impact that honey treatment might have on development of the early biofilm. Therefore, since biofilm development was not completely abrogated using $10 \%(\mathrm{w} / \mathrm{v})$ manuka honey, it is a possibility that arrested autoaggregation might have contributed to the prevention of biofilm development but that the process also relied on growth inhibition.

Wounds provide an environment that is rich in cell- and tissue-associated proteins such as fibronectin. Fibronectin forms part of the extracellular matrix and is associated with the epithelial cell surface. Damage caused to both cells and tissues in a wound exposes high levels of fibronectin that are available, not solely cell-bound, to which bacteria, including S. pyogenes, can adhere prior to colonization. Both fibronectin and high levels of fibrinogen are found in the plasma, which, as a consequence of vascular damage, is prevalent in wounds (Goodfellow et al., 2000). Fibronectinbinding proteins are expressed by all streptococci (Lannergård et al., 2005; Nobbs et al., 2009) but they differ in affinity for their substrate, and a number of them are able to bind to more than one ligand. Eleven fibronectin-binding proteins and five fibrinogen-binding proteins have been identified in S. pyogenes (Kreikemeyer et al., 2004; Nobbs et al., 2009) and are largely conserved throughout other streptococci. Such proteins are known to enhance biofilm formation (Bonifait et al., 2008) and their expression is highly regulated in response to numerous environmental stimuli (Kreikemeyer et al., 2003). As well as acting as binding ligands, human tissue proteins such as fibrinogen can also serve as a bridging molecule; in the case of S. aureus this has been found to be especially important during attachment to epithelial cells (Bonifait et al., 2008). Very little work has been undertaken to determine whether topical antimicrobial treatments can interrupt bacterial binding to human tissue proteins. To date, no studies on the effect of manuka or other honeys on bacterial biofilms have focussed on disruption of binding to a specific human protein ligand. This study has established that a sublethal concentration of manuka honey significantly reduced binding to human fibronectin $(P=0.01)$, but that binding to fibrinogen was not interrupted. This is the first time that a topical antimicrobial of any type, including manuka honey has been documented to inhibit bacterial binding to a host protein.

The fibronectin-binding protein $\mathrm{SfbI}$ is expressed by approximately $50 \%$ of invasive isolates of $S$. pyogenes and is regarded as one of the major adhesins and invasins (Medina et al., 2000). Sof is regarded as a major virulence factor that is known to contribute to pathogenesis of streptococcal infection in animal models (Courtney \& Pownall, 2010). The sof gene was first sequenced over 15 years ago (Rakonjac et al., 1995) and its product was found to be a surface bound protein of over $100 \mathrm{kDa}$, with a C-terminal domain comprised of numerous repeating peptides that bound to both fibronectin and fibrinogen (Courtney et al., 2003; Courtney \& Pownall, 2010). End point RT-PCR found that the genes encoding both of these proteins were differentially expressed in response to treatment with a sublethal dose of manuka honey. In both instances, reduced expression was noticeable, with levels of sof below the threshold of detection. The primary end point for determining the RNA extraction efficiency prior to RTPCR was total bacterial DNA, quantified using a NanoDrop. The half-life of bacterial mRNA is estimated to be between 0.5 and 20 min, but different RNA transcripts degrade at different rates. Studies with $S$. pyogenes have shown that 
degradation of transcripts can be broadly grouped into two classes (Bugrysheva \& Scott, 2010). Information concerning the half-life of the transcripts used in this study was not available; however, all RNA samples were handled and maintained in a manner designed to minimize degradation, as recommended (Promega). With this in mind, we feel confident that while the effect of the half-life of the RNA transcripts on the observed levels of RT-PCR product cannot be ignored, it is unlikely to be the sole reason for the differential levels of PCR product observed here.

Consequently it is possible that the reduction in expression of sof and $s f b I$ goes some way to explaining the significant reduction in fibronectin binding observed for S. pyogenes cells treated with $20 \%(\mathrm{w} / \mathrm{v})$ manuka honey. However, despite the reduced expression of sof, bacterial binding to fibrinogen was not similarly reduced. Sof is regarded as being one of the major fibrinogen binding proteins but it is not the only one, and others include $\mathrm{M}$ protein and Mrb (Hryniewicz et al., 1972; Kehoe, 1994). It is therefore possible that there is some level of redundancy amongst these fibrinogen binding proteins that means that despite reduced expression of Sof, fibrinogen binding remained unaffected. SfbI and Sof are also not the only fibronectinbinding proteins associated with $S$. pyogenes; others include FbaA, FbaB and SfbX (Jaffe et al., 1996; Terao et al., 2001, 2002; Jeng et al., 2003; Ramachandran et al., 2004), so it remains unclear as to why fibronectin binding was so drastically altered following honey treatment. It is a possibility that the reduction in fibronectin binding was a combination of reduced expression and specific physical disruption of binding or stearic hindrance by components of the manuka honey. This is an avenue that needs further investigation, but was outside the scope of this study.

Alternatively, it is a possibility that manuka honey could be affecting many of the major transcriptional regulatory circuits that govern expression of the numerous surface adhesins, such as the Mga regulon that controls expression of both aggregation and biofilm formation (Luo et al., 2008). If this is the case, it is likely that potentially many more genes than those studied here were being differentially expressed and affecting fibronectin binding. However, it was not possible to determine this during the study described here and further investigations will be necessary to confirm or dispel either of these hypotheses.

Honey is a complex substance estimated to be comprised of between 200 and 600 components, including fructose $(\sim 38.2 \%)$, glucose $(\sim 31.3 \%)$, sucrose $(1 \%)$ and 'other sugars' (9\%) (Bogdanov et al., 2008). Additional minor constituents include acids $(0.57 \%)$, proteins $(0.266 \%)$, amino acids $(0.1 \%)$, nitrogen $(0.41 \%)$, minerals $(0.17 \%)$ and in the case of manuka honey, methylglyoxal (MGO). The antibacterial action of manuka honey is attributed to its high osmolarity, low water activity and the presence of MGO; it is the combination of these factors that is thought to provide an unsuitable environment for bacterial growth (Cooper, 2008; Adams et al., 2009). The dilution of honey does not seem to affect the antimicrobial properties; MGO has been shown to remain active upon dilution but additional undefined factors are believed to maintain cidality when $\mathrm{MGO}$ is diluted below $0.53 \mathrm{mg} \mathrm{ml}-1$ (Jervis-Bardy et al., 2011). Unlike systemic antibiotics and other topical antimicrobials, the risk of bacterial resistance to manuka honey was low, even when high usage was maintained and to date, no 'honey-resistant' isolates have been found (Blair et al., 2009; Cooper et al., 2010). Therefore, manuka honey represents an efficacious and safe alternative to failing systemic and topical treatments that are currently used to treat wounds that are infected with $S$. pyogenes.

Taken collectively, the data described in this study indicate that manuka honey is effective at inhibiting the development of biofilms and disrupting established biofilms of S. pyogenes, and that this process is likely to be mediated by the specific interruption of binding to host tissue ligands, which in turn could be mediated in part by a differential expression of bacterial adhesins in response to honey treatment. Therefore, using the in vitro models described in this study, manuka honey was shown to have potential as a preventative measure against and treatment for wounds infected with S. pyogenes.

\section{ACKNOWLEDGEMENTS}

The authors would like to thank Paul Jones and Steve Potter for technical assistance; Howard Jenkinson for kindly providing MGAS6180 and Comvita for donating manuka honey to this study. M. S. L. worked under the European Centre for Training and Regional Co-operation scheme. This work was funded by the Development Fund at Cardiff Metropolitan University.

\section{REFERENCES}

Adams, C. J., Manley-Harris, M. \& Molan, P. C. (2009). The origin of methylglyoxal in New Zealand manuka (Leptospermum scoparium) honey. Carbohydr Res 344, 1050-1053.

Al-Waili, N. S., Akmal, M., Al-Waili, F. S., Saloom, K. Y. \& Ali, A. (2005). The antimicrobial potential of honey from United Arab Emirates on some microbial isolates. Med Sci Monit 11, BR433BR438.

Alandejani, T., Marsan, J., Ferris, W., Slinger, R. \& Chan, F. (2009). Effectiveness of honey on Staphylococcus aureus and Pseudomonas aeruginosa biofilms. Otolaryngol Head Neck Surg 141, 114-118.

Andrews, J. (2011). BSAC Methods for Antimicrobial Susceptibility Testing. British Society for Antimicrobial Chemotherapy. http://www. bsac.org.uk/Susceptibility+Testing/Susceptibility+Testing+Guide

Badet, C. \& Quero, F. (2011). The in vitro effect of manuka honeys on growth and adherence of oral bacteria. Anaerobe 17, 19-22.

Baldassarri, L., Creti, R., Recchia, S., Imperi, M., Facinelli, B., Giovanetti, E., Pataracchia, M., Alfarone, G. \& Orefici, G. (2006). Therapeutic failures of antibiotics used to treat macrolide-susceptible Streptococcus pyogenes infections may be due to biofilm formation. J Clin Microbiol 44, 2721-2727.

Blair, S. E., Cokcetin, N. N., Harry, E. J. \& Carter, D. A. (2009). The unusual antibacterial activity of medical-grade Leptospermum honey: 
antibacterial spectrum, resistance and transcriptome analysis. Eur J Clin Microbiol Infect Dis 28, 1199-1208.

Bogdanov, S., Jurendic, T., Sieber, R. \& Gallmann, P. (2008). Honey for nutrition and health: a review. J Am Coll Nutr 27, 677-689.

Bonifait, L., Grignon, L. \& Grenier, D. (2008). Fibrinogen induces biofilm formation by Streptococcus suis and enhances its antibiotic resistance. Appl Environ Microbiol 74, 4969-4972.

Bugrysheva, J. V. \& Scott, J. R. (2010). Regulation of virulence gene expression in Streptococcus pyogenes: determinants of differential mRNA decay. RNA Biol 7, 569-572.

Conley, J., Olson, M. E., Cook, L. S., Ceri, H., Phan, V. \& Davies, H. D. (2003). Biofilm formation by group a streptococci: is there a relationship with treatment failure? J Clin Microbiol 41, 4043-4048.

Cooper, R. A. (2005). Understanding wound infection. EWMA Position Document, pp. 2-5. London: MEP Ltd.

Cooper, R. (2008). Using honey to inhibit wound pathogens. Nurs Times 104, 46-49.

Cooper, R. A., Halas, E. \& Molan, P. C. (2002a). The efficacy of honey in inhibiting strains of Pseudomonas aeruginosa from infected burns. J Burn Care Rehabil 23, 366-370.

Cooper, R. A., Molan, P. C. \& Harding, K. G. (2002b). The sensitivity to honey of Gram-positive cocci of clinical significance isolated from wounds. J Appl Microbiol 93, 857-863.

Cooper, R. A., Jenkins, L., Henriques, A. F., Duggan, R. S. \& Burton, N. F. (2010). Absence of bacterial resistance to medical-grade manuka honey. Eur J Clin Microbiol Infect Dis 29, 1237-1241.

Cooper, R. A., Lindsay, E. \& Molan, P. C. (2011). Testing the susceptibility to manuka honey of streptococci isolated from wound swabs. J Apiprod Apimed Sci 3, 117-122.

Courtney, H. S. \& Pownall, H. J. (2010). The structure and function of serum opacity factor: a unique streptococcal virulence determinant that targets high-density lipoproteins. J Biomed Biotechnol 2010, 956071.

Courtney, H. S., Hasty, D. L. \& Dale, J. B. (2003). Serum opacity factor (SOF) of Streptococcus pyogenes evokes antibodies that opsonize homologous and heterologous SOF-positive serotypes of group A streptococci. Infect Immun 71, 5097-5103.

Edwards, A. M., Manetti, A. G. O., Falugi, F., Zingaretti, C., Capo, S., Buccato, S., Bensi, G., Telford, J. L., Margarit, I. \& Grandi, G. (2008). Scavenger receptor $g p 340$ aggregates group A streptococci by binding pili. Mol Microbiol 68, 1378-1394.

Enright, M. C., Spratt, B. G., Kalia, A., Cross, J. H. \& Bessen, D. E. (2001). Multilocus sequence typing of Streptococcus pyogenes and the relationships between emm type and clone. Infect Immun 69, 2416-2427.

Goodfellow, A. M., Hibble, M., Talay, S. R., Kreikemeyer, B., Currie, B. J., Sriprakash, K. S. \& Chhatwal, G. S. (2000). Distribution and antigenicity of fibronectin binding proteins (SfbI and SfbII) of Streptococcus pyogenes clinical isolates from the northern territory, Australia. J Clin Microbiol 38, 389-392.

Gottrup, F. (2008). Trends in surgical wound healing. Scand J Surg 97, 220-225, discussion 225-226.

Green, N. M., Zhang, S., Porcella, S. F., Nagiec, M. J., Barbian, K. D., Beres, S. B., LeFebvre, R. B. \& Musser, J. M. (2005). Genome sequence of a serotype M28 strain of group a streptococcus: potential new insights into puerperal sepsis and bacterial disease specificity. J Infect Dis 192, 760-770.

Guo, S. \& Dipietro, L. A. (2010). Factors affecting wound healing. J Dent Res 89, 219-229.

Henriques, A. F., Jenkins, R. E., Burton, N. F. \& Cooper, R. A. (2010). The intracellular effects of manuka honey on Staphylococcus aureus. Eur J Clin Microbiol Infect Dis 29, 45-50.
Henriques, A. F., Jenkins, R. E., Burton, N. F. \& Cooper, R. A. (2011). The effect of manuka honey on the structure of Pseudomonas aeruginosa. Eur J Clin Microbiol Infect Dis 30, 167-171.

Hryniewicz, W., Lipinski, B. \& Jeljaszewicz, J. (1972). Nature of the interaction between $\mathrm{M}$ protein of Streptococcus pyogenes and fibrinogen. J Infect Dis 125, 626-630.

Jaffe, J., Natanson-Yaron, S., Caparon, M. G. \& Hanski, E. (1996). Protein F2, a novel fibronectin-binding protein from Streptococcus pyogenes, possesses two binding domains. Mol Microbiol 21, 373-384.

Jakubovics, N. S., Kerrigan, S. W., Nobbs, A. H., Strömberg, N., van Dolleweerd, C. J., Cox, D. M., Kelly, C. G. \& Jenkinson, H. F. (2005). Functions of cell surface-anchored antigen I/II family and Hsa polypeptides in interactions of Streptococcus gordonii with host receptors. Infect Immun 73, 6629-6638.

Jakubovics, N. S., Brittan, J. L., Dutton, L. C. \& Jenkinson, H. F. (2009). Multiple adhesin proteins on the cell surface of Streptococcus gordonii are involved in adhesion to human fibronectin. Microbiology 155, 3572-3580.

James, G. A., Swogger, E., Wolcott, R., Pulcini, E., Secor, P., Sestrich, J., Costerton, J. W. \& Stewart, P. S. (2008). Biofilms in chronic wounds. Wound Repair Regen 16, 37-44.

Jeng, A., Sakota, V., Li, Z., Datta, V., Beall, B. \& Nizet, V. (2003). Molecular genetic analysis of a group A Streptococcus operon encoding serum opacity factor and a novel fibronectin-binding protein, SfbX. J Bacteriol 185, 1208-1217.

Jenkins, R., Burton, N. \& Cooper, R. (2011a). Effect of manuka honey on the expression of universal stress protein A in meticillin-resistant Staphylococcus aureus. Int J Antimicrob Agents 37, 373-376.

Jenkins, R., Burton, N. \& Cooper, R. (2011b). Manuka honey inhibits cell division in methicillin-resistant Staphylococcus aureus. J Antimicrob Chemother 66, 2536-2542.

Jervis-Bardy, J., Foreman, A., Bray, S., Tan, L. \& Wormald, P. J. (2011). Methylglyoxal-infused honey mimics the anti-Staphylococcus aureus biofilm activity of manuka honey: potential implication in chronic rhinosinusitis. Laryngoscope 121, 1104-1107.

Kalia, A., Enright, M. C., Spratt, B. G. \& Bessen, D. E. (2001). Directional gene movement from human-pathogenic to commensallike streptococci. Infect Immun 69, 4858-4869.

Kehoe, M. A. (1994). Cell-wall-associated proteins in Gram positive bacteria. In Bacterial Cell Wall, New Comprehensive Biochemistry, vol. 27, pp. 217-261. Edited by J.-M. Ghuysen \& R. Hakenbeck. Amsterdam: Elsevier.

Köller, T., Manetti, A. G., Kreikemeyer, B., Lembke, C., Margarit, I., Grandi, G. \& Podbielski, A. (2010). Typing of the pilus-proteinencoding FCT region and biofilm formation as novel parameters in epidemiological investigations of Streptococcus pyogenes isolates from various infection sites. J Med Microbiol 59, 442-452.

Kreikemeyer, B., Mclver, K. S. \& Podbielski, A. (2003). Virulence factor regulation and regulatory networks in Streptococcus pyogenes and their impact on pathogen-host interactions. Trends Microbiol 11, 224-232.

Kreikemeyer, B., Oehmcke, S., Nakata, M., Hoffrogge, R. \& Podbielski, A. (2004). Streptococcus pyogenes fibronectin-binding protein F2: expression profile, binding characteristics, and impact on eukaryotic cell interactions. J Biol Chem 279, 15850-15859.

Kreikemeyer, B., Gámez, G., Margarit, I., Giard, J. C., Hammerschmidt, S., Hartke, A. \& Podbielski, A. (2011). Genomic organization, structure, regulation and pathogenic role of pilus constituents in major pathogenic Streptococci and Enterococci. Int $J$ Med Microbiol 301, 240-251.

Kubo, M., Van de Water, L., Plantefaber, L. C., Mosesson, M. W., Simon, M., Tonnesen, M. G., Taichman, L. \& Clark, R. A. (2001). 
Fibrinogen and fibrin are anti-adhesive for keratinocytes: a mechanism for fibrin eschar slough during wound repair. J Invest Dermatol 117, 1369-1381.

Lannergård, J., Flock, M., Johansson, S., Flock, J. I. \& Guss, B. (2005). Studies of fibronectin-binding proteins of Streptococcus equi. Infect Immun 73, 7243-7251.

Lembke, C., Podbielski, A., Hidalgo-Grass, C., Jonas, L., Hanski, E. \& Kreikemeyer, B. (2006). Characterization of biofilm formation by clinically relevant serotypes of group A streptococci. Appl Environ Microbiol 72, 2864-2875.

Luo, F., Lizano, S., Banik, S., Zhang, H. \& Bessen, D. E. (2008). Role of Mga in group A streptococcal infection at the skin epithelium. Microb Pathog 45, 217-224.

Lyon, W. R., Gibson, C. M. \& Caparon, M. G. (1998). A role for trigger factor and an rgg-like regulator in the transcription, secretion and processing of the cysteine proteinase of Streptococcus pyogenes. EMBO J 17, 6263-6275.

Maddocks, S. E., Wright, C. J., Nobbs, A. H., Brittan, J. L., Franklin, L., Strömberg, N., Kadioglu, A., Jepson, M. A. \& Jenkinson, H. F. (2011). Streptococcus pyogenes antigen I/II-family polypeptide AspA shows differential ligand-binding properties and mediates biofilm formation. Mol Microbiol 81, 1034-1049.

Mavric, E., Wittmann, S., Barth, G. \& Henle, T. (2008). Identification and quantification of methylglyoxal as the dominant antibacterial constituent of Manuka (Leptospermum scoparium) honeys from New Zealand. Mol Nutr Food Res 52, 483-489.

Medina, E., Schulze, K., Chhatwal, G. S. \& Guzmán, C. A. (2000). Nonimmune interaction of the SfbI protein of Streptococcus pyogenes with the immunoglobulin $\mathrm{G} \mathrm{F}\left(\mathrm{ab}^{\prime}\right)(2)$ fragment. Infect Immun 68, 4786-4788.

Merckoll, P., Jonassen, T. Ø., Vad, M. E., Jeansson, S. L. \& Melby, K. K. (2009). Bacteria, biofilm and honey: a study of the effects of honey on 'planktonic' and biofilm-embedded chronic wound bacteria. Scand J Infect Dis 41, 341-347.

Miles, A. A., Misra, S. S. \& Irwin, J. O. (1938). The estimation of the bactericidal power of the blood. J Hyg (Lond) 38, 732-749.

Molan, P. C. (1992). The antibacterial activity of honey. 1 . The nature of the antibacterial activity. Bee World 73, 5-28.

Nassar, H. M., Li, M. \& Gregory, R. L. (2012). Effect of honey on Streptococcus mutans growth and biofilm formation. Appl Environ Microbiol 78, 536-540.

Nobbs, A. H., Lamont, R. J. \& Jenkinson, H. F. (2009). Streptococcus adherence and colonization. Microbiol Mol Biol Rev 73, 407-450.

Ogunmwonyi, I. H., Mazomba, N., Mabinya, L., Ngwenya, E., Green, E., Akinpelu, D. A., Olaniran, A. O. \& Okoh, A. I. (2010). In vitro time-kill studies of antibacterial agents from putative marine Streptomyces species isolated from the Nahoon beach, South Africa. African J Pharm Pharmacol 4, 908-916.

Okahashi, N., Nakata, M., Sakurai, A., Terao, Y., Hoshino, T., Yamaguchi, M., Isoda, R., Sumitomo, T., Nakano, K. \& other authors (2010). Pili of oral Streptococcus sanguinis bind to fibronectin and contribute to cell adhesion. Biochem Biophys Res Commun 391, 11921196.

Okhiria, O. A., Henriques, A. F. M., Burton, N. F. \& Cooper, R. A. (2009). Honey modulates biofilms of Pseudomonas aeruginosa in a time and dose dependent manner. J Apiprod ApiMed Sci 1, 6-10.

Oliveira, M. R., Napimoga, M. H., Cogo, K., Gonçalves, R. B., Macedo, M. L., Freire, M. G. \& Groppo, F. C. (2007). Inhibition of bacterial adherence to saliva-coated through plant lectins. J Oral Sci 49, 141-145.

Rakonjac, J. V., Robbins, J. C. \& Fischetti, V. A. (1995). DNA sequence of the serum opacity factor of group A streptococci: identification of a fibronectin-binding repeat domain. Infect Immun 63, 622-631.

Ramachandran, V., McArthur, J. D., Behm, C. E., Gutzeit, C., Dowton, M., Fagan, P. K., Towers, R., Currie, B., Sriprakash, K. S. \& Walker, M. J. (2004). Two distinct genotypes of prtF2, encoding a fibronectin binding protein, and evolution of the gene family in Streptococcus pyogenes. J Bacteriol 186, 7601-7609.

Rhoads, D. D., Wolcott, R. D. \& Percival, S. L. (2008). Biofilms in wounds: management strategies. J Wound Care 17, 502-508.

Terao, Y., Kawabata, S., Kunitomo, E., Murakami, J., Nakagawa, I. \& Hamada, S. (2001). Fba, a novel fibronectin-binding protein from Streptococcus pyogenes, promotes bacterial entry into epithelial cells, and the fba gene is positively transcribed under the Mga regulator. Mol Microbiol 42, 75-86.

Terao, Y., Kawabata, S., Nakata, M., Nakagawa, I. \& Hamada, S. (2002). Molecular characterization of a novel fibronectin-binding protein of Streptococcus pyogenes strains isolated from toxic shock-like syndrome patients. J Biol Chem 277, 47428-47435.

Thenmozhi, R., Balaji, K., Kumar, R., Rao, T. S. \& Pandian, S. K. (2011). Characterization of biofilms in different clinical $M$ serotypes of Streptococcus pyogenes. J Basic Microbiol 51, 196-204.

Voidarou, C., Alexopoulos, A., Plessas, S., Karapanou, A., Mantzourani, I., Stavropoulou, E., Fotou, K., Tzora, A., Skoufos, I. \& Bezirtzoglou, E. (2011). Antibacterial activity of different honeys against pathogenic bacteria. Anaerobe 17, 375-379.

Werdin, F., Tennenhaus, M., Schaller, H. E. \& Rennekampff, H. O. (2009). Evidence-based management strategies for treatment of chronic wounds. Eplasty 9 , e19.

Edited by: R. J. Palmer 